\title{
¿Quién defiende a las defensoras? Género, etnia y derecho al acceso a la justicia en los tiempos del conflicto ambiental en Chile
}

\author{
Who is protecting the advocates? \\ Gender, ethnicity and the right to Access to justice during the environmental \\ conflict in Chile
}

\section{ISSN 2071-8748 \\ E-ISSN 2218-3345 \\ (c) (1) (2) \\ BY NC SA}

DOI: https://doi.org/10.5377/entorno.v0i69.9569

URI: http://hdl.handle.net/11298/1162

\author{
Natalia Acevedo-Castillo \\ Universidad Alberto Hurtado \\ naacevedo.c@gmail.com \\ https://orcid.org/0000-0002-5233-9845 \\ Catalina Laso-Samsing \\ Universidad Alberto Hurtado \\ clasosamsing@gmail.com, \\ https://orcid.org/0000-0001-6291-1289 \\ Rocío Norambuena-Avilés \\ Universidad Alberto Hurtado \\ rocio.nora.aviles@gmail.com \\ https://orcid.org/0000-0002-2939-3034
}

Recibido: 6 de enero 2020

Aceptado: 27 de junio de 2020

\section{Resumen}

La presente investigación examinó el marco legal y judicial chileno a fin de dilucidar si este garantiza la efectiva tutela de derechos de un grupo en situación de riesgo, como son las mujeres defensoras del medio ambiente. Se contrastaron, tanto las vías disponibles en chile como el comportamiento exhibido por el Estado en la protección de las defensoras ambientales, con los estándares establecidos en el Derecho Internacional, incluyendo el acuerdo de Escazú, no ratificado por Chile. Se realizó una contextualización teórica del problema y se proyectó la factibilidad de éxito de cada una de las vías judiciales identificadas. Entre las conclusiones, se detectó una falta

\section{Abstract}

The legal and judicial framework in Chile were examined in this research with the objective to explain whether this guarantees an effective protection of the rights of an atrisk group: those women who protect the environment. Both the available routes and the behavior of the State were contrasted in relation to the protection of the women who advocate and defend the environment. This was carried out based on the standards established by the International Law, including the Escazú Agreement, which was not ratified by Chile. A theoretical contextualization of the problem was made and the feasibility for sucess in each of the identified judicial routes was projected. 
de acciones judiciales que resguarden apropiadamente los derechos de las mujeres defensoras ambientales y se propuso un modelo de acción alternativa que permita garantizar un efectivo acceso a la justicia.

\section{Palabras clave}

Mujeres - Situación legal - Chile; Asistencia legal a mujeres - acuerdo de Escazú - Chile; Acción y defensa (derecho) Chile; Mujeres trabajadoras por los derechos humanos Chile.

\section{Introducción}

América Latina es fácilmente el continente más riesgoso para dedicarse al activismo ambiental. A 2017, las cifras de Global Witness son categóricas en señalar que tiene el dudoso récord de concentrar el $60 \%$ de los asesinatos de personas defensoras del ambiente en el mundo (Global Witness, 2016). El tema ya ha despertado alarmas en instancias internacionales, como lo demuestra la adopción del Acuerdo de Escazú, que contempla específicamente un apartado sobre la seguridad de las y los defensores ambientales en América Latina. ${ }^{1}$

Una de las características principales del conflicto ambiental es la asimetría: en los recursos, en la información y en el poder. La observación de la realidad ha demostrado que este balance solo se agudiza cuando son las mujeres las que están defendiendo el medio ambiente y sus tierras. Las defensoras ambientales -a menudo mujeres pertenecientes a pueblos originarios, residentes en áreas rurales-enfrentan un tipo muy específico de persecución, que va desde la judicialización o criminalización de su activismo, pasando por su estigmatización como "brujas", "enemigas del desarrollo" y ataques constitutivos de violencia sexual experimentados tanto dentro como fuera de sus comunidades hasta las formas más sutiles de hostigamiento por parte de múltiples agentes. Muchos de estos hechos son constitutivos de delito, otros tantos corresponden a una vulneración manifiesta de sus derechos fundamentales. En este escenario, ¿qué hace el Estado?
Among its conclusions, a lack of judicial actions to appropriately guard the rights of women in defense of the environment was found. It was recommended to have an alternative action model that allows to guarantee an effective access to justice.

\section{Keywords}

Key words: Women - Legal situation - Chile; Legal assistance to women - Escazú accord - Chile; Action and defense (law/right) - Chile; Women at work for human rights - Chile.

\section{Metodología}

La presente investigación tiene como objetivo general visibilizar la serie de dificultades que atraviesan las mujeres activistas medioambientales para acceder a la justicia respecto de aquellas amenazas y vulneraciones sufridas a sus derechos fundamentales, como consecuencia del ejercicio de su activismo. Igualmente, se espera problematizar sobre la inactividad del Estado en su papel de garante de derechos fundamentales como la tutela judicial efectiva, la integridad física y psíquica, el derecho a la vida y el derecho a vivir en un medio ambiente libre de contaminación.

Los objetivos específicos, en cambio, serán los consistentes en:

- Relacionar elementos como la condición de género femenino y la pertenencia a un pueblo originario, como factores de riesgos específicos en el activismo medioambiental.

- Identificar los problemas concretos que enfrentan las activistas medioambientales.

- Denunciar las insuficiencias del Estado, tanto en su vertiente de Estado-administrador como Estado-juez, en el cumplimiento de su deber de garantizar acceso a la justicia, estudiando sus acciones (o falta de ellas) ante la problemática descrita.

En cuanto a la metodología utilizada, se optó por una investigación cualitativa de carácter exploratorio que se valió de las técnicas de análisis de documentos, análisis normativo (tratados internacionales, en particular Escazú,

1 Cabe señalar que Chile no firmó el Acuerdo de Escazú, pese a haber sido uno de sus principales impulsores, frenando así el avance de medidas contra la criminalización y vulneración de los derechos de las personas defensoras ambientales. 
Belén do Pará, Convenio 169 OIT, y en el contexto nacional, la Constitución Política de la República, Código Penal e instrucciones de la Fiscalía) y solicitudes de transparencia a la Fiscalía y organismos persecutores.

Ni la tierra ni las mujeres: la estrecha relación entre la violencia contra las mujeres y la depredación medioambiental.

Es necesario abordar el problema desde una perspectiva estructural considerando las diversas interacciones de sistemas, como son el patriarcado, el capitalismo y las consecuencias de la colonización en América Latina. Es en esto donde la teoría unitaria de Cinzia Arruza resulta de gran ayuda. Arruza postula la superposición del sistema patriarcal y el capitalismo, siendo la principal tarea observar cómo estos sistemas se particularizan y resignifican con el tiempo, fusionándose y complementándose para crear nuevas y más complejas formas de opresión, obedeciendo a nuevas formas de dominación y subordinación de las mujeres y demás sujetos precarizados (Arruza, citada en Follegati, 2019), dejándonos con la retroalimentación de dos sistemas de opresión que, para el caso específico de las mujeres defensoras del medio ambiente, parecen actuar en forma conjunta y cómplice. Un ejemplo temprano de este análisis aparece en los textos de Vandana Shiva, que explicita que el capitalismo, en su búsqueda por la uniformidad y la imposición del monocultivo, desprecia toda diversidad natural y a toda persona que intente preservarla. En India, las guardianas históricas de las semillas y, por tanto, encargadas de la preservación y perpetuación de la biodiversidad, han sido las mujeres, lo que les ha valido transformarse en blancos inmediatos de las amenazas de las empresas transnacionales que toman como primera medida el silenciamiento de sus voces y la pérdida de esa sabiduría ancestral en pro de imponer un sistema occidentalizado de cultivo basado en la uniformidad de la naturaleza (Miles y Shiva, 1998).

Nada de esto es al azar. Silvia Federici aclara que la violencia fue el principal medio utilizado por los colonizadores para implementar un sistema de desarrollo capitalista a través de la apropiación de los territorios conquistados y la instalación de una jerarquía masculina basada en la economía de occidente (Federici, citada por Follegati, Luna, 2019). El rasgo basal común al patriarcado, el capitalismo y la colonización es la violencia, principal medio utilizado por el hombre blanco colonizador para implementar un sistema capitalista basado en la apropiación forzosa de los territorios conquistados y la instalación de un desarrollo basado en la jerarquía de lo masculino y lo occidental. En Latinoamérica, Luna Follegati cita a Rita Segato y establece la particularidad surgida durante la Conquista y la Colonia, periodo en que los derechos de las mujeres se violentaron bajo las formas adquiridas por el derecho masculino y territorial que fusiona aspectos de las vertientes indígena, europea y occidental, complementándose en un nuevo tipo de sistema patriarcal y volviendo el cuerpo de las mujeres a la vez presa y territorio de disputa (Segato, citada en Follegati, 2019).

Aquí se introduce a la segunda sujeto de opresión: la naturaleza. La autora Francisca Fernández resume que la instauración de este patriarcado capitalista permitió que la visión cientificista, colonial y patriarcal de las sociedades modernas la colocase como un sistema por ser dominado e hizo de esa dominación el eje del progreso de la humanidad. En esta misma dinámica de dominación, se colocó lo femenino, lo indígena, lo afro y lo infantil como parte de la naturaleza en tanto estado salvaje, en contraposición con la cultura entendida como lo masculino, racional $y$, por ende, civilizado. La apropiación de la naturaleza devino en el modelo de explotación que se debía replicar, perpetuándose en la opresión hacia las mujeres mediante la dominación de los cuerpos y otras territorialidades en cuanto concebidos como espacios de conquista por parte del ente capitalista y patriarcal (Fernández, 2019). Así, la opresión de las mujeres y la depredación del medio ambiente están inexorablemente unidos por la identificación que el ideario patriarcal/capitalista les ha asignado como agentes salvajes e irracionales. La tarea del hombre es mantener bajo estricto control el cuerpo y la vida de las mujeres de la misma forma en que es la carga del hombre blanco domar lo salvaje, conquistar la naturaleza y civilizar los pueblos bárbaros que osaban habitarla.

En este sentido, de la misma forma en que la explotación natural se sostiene en el capitalismo y el modelo extractivista neoliberal, García Torres plantea que el patriarcado y el colonialismo naturalizan la desigualdad en tanto mecanismos de producción, reproducción y legitimación de los poderes hegemónicos, erigiendo en el poder a un 
determinado sujeto: el varón, blanco, con poder adquisitivo, heterosexual (García Torres, citada en Fernández, 2019). Para este sistema, tanto la naturaleza como las mujeres son un objeto, un territorio para ser tomado y explotado según el capricho de los "productores" que llevan en sus hombros la perpetuación del desarrollo de la humanidad, la humanidad entendida como formada por sujetos de derechos, y sujetos de derechos entendidos como este hombre blanco con poder adquisitivo y heterosexual. La naturaleza y las mujeres valen en cuanto producen $-\mathrm{y}$ se reproduceny en tanto perpetúan la economía masculinizada del extractivismo. Las mujeres que defienden a la naturaleza en tanto sujeto explotado, afectado por una opresión símil a la que ellas sufren, entonces, cometen una infracción múltiple: fallan como mujeres al patriarcado, como trabajadoras reproductoras al capitalismo y como individuas civilizadas al colonialismo, amenazan con intentar volver al "estado de naturaleza" salvaje del que el hombre blanco las rescató hace tantos siglos y que le concedió el divino derecho de permanecer ad eternum en el poder, explotando para su ganancia al enemigo conquistado.

\section{¿A qué se enfrentan las defensoras?}

En las últimas décadas el continente latinoamericano ha sido testigo del "progreso" que múltiples transnacionales han traído a la región, innumerables megaproyectos que buscan insaciablemente la explotación de los recursos mineros, hidrocarburantes y agroforestales de nuestras tierras, en otras palabras, la destrucción de miles de ecosistemas, biodiversidades, comunidades y pueblos.

En este contexto de progreso y desarrollo de América Latina, la vida e integridad física y psíquica de quienes entorpecen el objetivo de las transnacionales está en peligro, debido a los constantes enfrentamientos en los que se ven involucrados con estos agentes. Al respecto, el Fondo de Acción Urgente (2016) ha señalado que "la resistencia que ofrecen las comunidades y sus organizaciones en defensa de sus proyectos comunitarios, es traducida bajo la etiqueta de conflictos ambientales en los que la respuesta de los agentes públicos y privados, lejos de morigerar las amenazas en ciernes, acentúa las agresiones y los impactos en materia de derechos humanos" (p. 7).
Algunas cifras sobre los conflictos ambientales:

- La iniciativa de Global Witness, durante el año 2017, contabilizó el asesinato de 207 personas defensoras de la tierra y el medio ambiente (Global Witness, 2017).

- Casi el $60 \%$ de las personas defensoras de la tierra y el medio ambiente asesinadas eran de América Latina (Global Witness, 2017).

- Brasil fue el país que presentó la mayor cantidad de asesinatos, 57 personas defensoras de la tierra y el medio ambiente, para ser exactos (Global Witness, 2017).

La agroindustria fue el sector más peligroso, superando a la minería. Las grandes plantaciones de palma aceitera; café; frutas tropicales; caña de azúcar; algodón; soya y la ganadería, son algunas de estas industrias (Global Witness, 2017).

¿Qué sucede con las mujeres defensoras de los derechos ambientales, los territorios y la naturaleza? De acuerdo con la información recopilada por Global Witness, 9 de cada 10 activistas medioambientales asesinados eran hombres. Sin embargo, es relevante destacar que las defensoras enfrentan amenazas específicas en razón de su condición de género, las cuales incluyen: la violencia sexual, agresiones físicas, la criminalización de su activismo, campañas de difamación, amenazas contra sus familias, insultos misóginos, entre otras (Global Witness, 2017). Las cifras que reflejan este tipo de agresiones son alarmantes. Solamente entre los años 2012 y 2014 la Iniciativa Mesoamericana de Mujeres Defensoras de Derechos Humanos registró un total de 1.688 agresiones a mujeres defensoras de derechos humanos en El Salvador, Guatemala, Honduras y México (IM-Defensoras, 2012-2014).

En una primera aproximación para lograr entender estas agresiones y formas de criminalización de las mujeres defensoras, es necesario conocer a las víctimas de estas conductas. Al respecto, es de vital importancia destacar que en la mayoría de los casos podemos observar alarmas de interseccionalidad, donde un gran porcentaje de las víctimas son mujeres pertenecientes a pueblos originarios que habitan sectores rurales, además de encontrarse en precariedad económica.

En una segunda instancia debe identificarse quienes son los sujetos activos de estas conductas. Los estudios 
antedichos han señalado que estas amenazas y ataques contra su vida, integridad, seguridad y movilidad provienen de múltiples actores, como las empresas, fuerzas militares, la delincuencia, los grupos paramilitares o, incluso, los miembros de las propias comunidades afines a los proyectos empresariales, entre otros (Fondo de Acción Urgente, 2016).

Para finalizar la compresión de este fenómeno, ha de atenderse al concepto de la criminalización y las modalidades en las que puede presentarse. En términos generales se puede definir la criminalización como "el proceso mediante el cual se van asociando a ciertas conductas y sujetos el carácter de potenciales criminales (...) actuando como justificativo de medidas de fuerza de carácter preventivo" (Acuña, Fredes y Pérez, 2010, p. 365). Entonces, en términos particulares, la criminalización se puede entender como un proceso que involucra una multiplicidad de acciones que buscan neutralizar las capacidades de acción de las defensoras, ya sea por las vías de aparente legalidad (como el uso de la fuerza y la intervención de las instancias judiciales o administrativas) o por las vías de hecho e ilegales [como los hostigamientos, las amenazas, interceptaciones, la estigmatización de sus luchas y de su propia persona, entre otras] (Fondo de Acción Urgente, 2016). Es decir, la criminalización se da de tres modos: por medio de la judicialización de las defensoras, de su estigmatización y a través de diversas formas de hostigamiento relacionadas con su condición de género (Fondo de Acción Urgente, 2016).

Se inicia el estudio de las formas de criminalización por las vías de aparente legalidad, es decir, la judicialización de las defensoras. Esta modalidad consiste en una forma de disciplinar y de castigo social de los líderes y lideresas de la defensa del medio ambiente al considerar su resistencia a los proyectos empresariales como un delito y a ellos como unos delincuentes, lo que claramente viola el principio de "responsabilidad penal individual" (Fondo de Acción Urgente, 2016). La neutralización de las resistencias medioambientales bajo la jurisdicción penal se da, en, por lo menos, tres etapas: primero, con la creación de tipos penales direccionados a contener la protesta social, para luego iniciar procedimientos penales en contra de quienes se resisten, finalizando con la aplicación efectiva de penas como ejercicio de disciplina social (Fondo de Acción Urgente, 2016).
Dentro de los múltiples casos de judicialización de los que se tiene registro en Latinoamérica, es posible citar el de la Machi Millaray Hichalaf. En enero del 2013 fue acusada, junto a otros miembros de su comunidad, de tenencia de armas y encubrimiento de incendio, debiendo permanecer cuatro meses en prisión preventiva en una cárcel de máxima seguridad en Valdivia, Chile. Carabineros allanó su casa utilizando armamento de largo alcance, intentó despojarla de sus prendas e incautó bienes como "evidencia" sin mediar autorización judicial alguna. La Machi Millaray lideraba la lucha comunitaria por las tierras donde habitan las comunidades mapuches de Maihue, Roble-Carimallín y Lumaco, lugar en que buscaba instalarse la Central Hidroeléctrica Osorno. Tras nueve meses de un proceso penal en su contra, fue la única del grupo en ser condenada, pese a que todos fueron juzgados por el mismo delito y bajo las mismas pruebas, lo que demuestra claramente que fue víctima de una criminalización en razón de su género y por su papel en la comunidad en su calidad de Machi (Fondo de Acción Urgente, 2016).

Por su parte, las vías de hecho e ilegales se configuran por una multiplicidad de actos de agresión. Esta violencia hacia las defensoras se puede manifestar a través de las distintas formas de hostigamiento, tanto por parte de agentes estatales como de los trabajadores de las empresas, sus representantes e incluso los miembros de sus comunidades afines a los proyectos. Estas agresiones responden a lógicas de abusos de poder y pueden adoptar diversas formas, las cuales van desde sutiles formas de precarización de su vida a través de insultos, actos de apartheid en la vida cotidiana, el fomento de rumores hasta amenazas personales o contra miembros de su familia; desde campañas de difamación hasta acciones aún más graves como las de inteligencia ofensiva, amenazas de muerte, agresiones físicas y sexuales, secuestros, acoso judicial, asesinatos u otras formas de hostigamientos e intimidación policial (Fondo de Acción Urgente, 2016).

Estas múltiples formas de hostigamiento pueden verse ilustradas en el caso de Macarena la Negra Valdés. Tras cuatro años de férrea oposición a la construcción de la hidroeléctrica Mini Central de Paso Tranguil, Macarena fue encontrada ahorcada en su casa el día 22 de agosto de 2016. Al día siguiente, RP Global comenzó con las faenas de 
instalación del cableado de alta tensión sin la autorización de los propietarios de dichos terrenos y apoyados por Carabineros, quienes se negaron a entregar información del procedimiento y arrestaron a quienes les solicitaron explicaciones. Si bien el Ministerio Público intentó archivar el caso tras concluir que su muerte se trataba de un suicidio, fue obligado a perseverar por el Tribunal de Garantía de Panguipulli,. No obstante, a 2019 no existen nuevos antecedentes. La familia de Macarena logró realizar una segunda autopsia particular que desmiente la hipótesis de suicidio, arrojando que las lesiones de estrangulación fueron infringidas post mortem evidenciando el montaje judicial en su crimen (Fondo de Acción Urgente, 2018).

Por último, es posible mencionar la estigmatización a la que se ven expuestas las defensoras, la cual busca de forma intencional restar legitimidad al trabajo de defensa de los derechos humanos que realizan, como también señalar y dañar la imagen pública de estas. En esta modalidad de criminalización juegan un papel crucial los medios de comunicación, casi siempre afines a los intereses de la industria extractiva, cuyos mensajes influyen en la percepción que se tiene de las defensoras y sus luchas, representándolas como una amenaza al orden social. Lo dicho por los medios de comunicación se hace eco de los trabajadores de las empresas y de los miembros de las comunidades afectadas, quienes se sienten facultados para agredir de diversas formas a las defensoras y a sus familias (Fondo de Acción Urgente, 2016).

La estigmatización se lleva a cabo con el objetivo de denigrar a las defensoras, apunta directamente a impactarlas psicológica, física, emocional y sexualmente, reforzando imaginarios errados en su entorno familiar, comunitario, organizativo y social que dificultan, y muchas veces anulan, sus protagonismos en el ámbito público y su ejercicio de defensa de derechos ambientales y territoriales (Fondo de Acción Urgente, 2016).

Un ejemplo de estigmatización es el caso del linchamiento mediático sufrido por la defensora Esperanza Martínez, en el contexto de explotación de hidrocarburos en zonas protegidas del Ecuador: desde su participación como asesora en el proceso de la Asamblea Nacional Constituyente, empezó a ser objeto de manifestaciones hostiles por parte de agentes privados y públicos, incluso por el mismo expresidente de Ecuador, Rafael Correa, quien se refirió a ella públicamente como "ecologista infantil", "fundamentalista", "argolla" o "tranquera", situándola en la palestra pública como una enemiga de su proyecto político; llegó incluso a calificarla como "la mentirosa del año" cuando ella denunció la construcción de una carretera en el parque Yasuní. Frente a la inacción de la administración de justicia y la Defensoría del Pueblo a estos ataques mediáticos, la activista debió responder a los insultos y a la presión derivada de estos, por medio de cartas abiertas (Fondo de Acción Urgente, 2016).

Qué tiene que decir el derecho en materia de defensoras ambientales.

El contexto normativo chileno en materia de defensoras ambientales es difuso, ya que respecto a las mujeres que defienden el medio ambiente es posible reconocer diversas dimensiones de interseccionalidad. En primer lugar, se trata de mujeres. Como segundo criterio encontramos que, con frecuencia, las defensoras ambientales son parte de algún pueblo originario, lo que suele explicarse en el carácter sagrado que el medio ambiente tiene para su cosmovisión. Y como tercer elemento, consecuencia de lo anterior, suele tratarse de mujeres empobrecidas.

Esta interseccionalidad implica que le sean aplicables diversas normas, tanto en el ámbito nacional como internacional. En cuanto a los tratados internacionales de derechos humanos, son pertinentes la Convención sobre la Eliminación de todas las Formas de Discriminación contra la Mujer, ratificada por Chile en el año 1989, y la Convención Internacional sobre la Eliminación de todas las Formas de Discriminación Racial, ratificada en 1971. Respecto de esta última, es especialmente relevante el artículo 5.0, literales a y b, las cuales señalan la obligación del Estado en torno a la eliminación de la discriminación y garantizar la igualdad ante la ley, sin distinción de raza, color y origen nacional o étnico; en particular los derechos a la igualdad de tratamiento en los tribunales y todos los demás órganos que administran justicia; y el derecho a la seguridad personal y a la protección del Estado contra todo acto de violencia o atentado contra la integridad personal cometido por funcionarios públicos o por cualquier individuo, grupo o institución. 


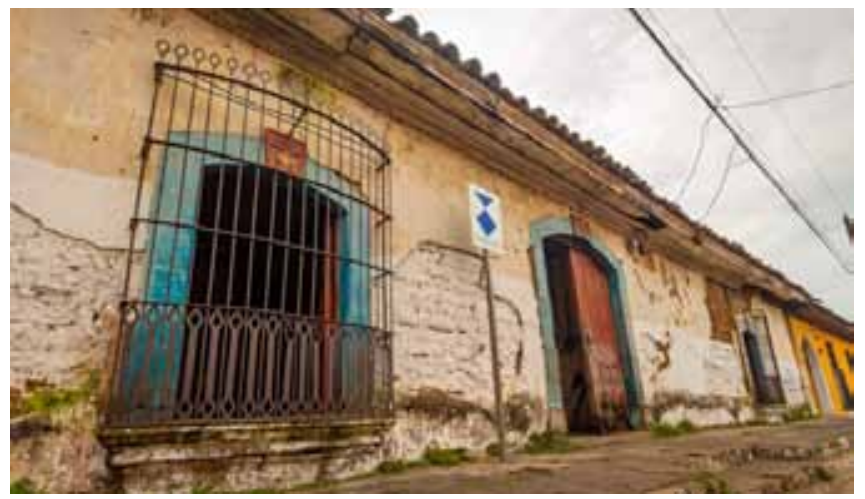

Otra norma supranacional relevante es el Acuerdo de Escazú, convenio latinoamericano relativo al medioambiente que tiene la particularidad y relevancia de incluir, por primera vez, disposiciones relativas a la protección de las defensoras y defensoras de derechos humanos en asuntos ambientales. Si bien Chile lideró las negociaciones para firmar este acuerdo, a la fecha aún no lo ha ratificado, lo que implica que sus disposiciones no han pasado a formar parte del ordenamiento vigente.

En el ámbito nacional, dentro de la Constitución Política de la República de Chile existe una serie de derechos que son aplicables a los casos de defensoras ambientales. En primer lugar, el artículo 19, numeral 1, el cual consagra el derecho a la vida y a la integridad física y psíquica; el 19, numeral 2, que establece expresamente la igualdad entre hombres y mujeres; el artículo 19, numeral 3, relativo a la igual protección de la ley en el ejercicio de los derechos; 19, numeral 7, libertad personal y seguridad individual; y el artículo 19, numeral 8, consagra el derecho a vivir en un medio ambiente libre de contaminación.

Del catálogo de derechos recién mencionados, es posible desprender que el Estado de Chile tiene una serie de obligaciones, tanto nacionales como internacionales, relativas a la adecuada protección de las defensoras ambientales; obligaciones que son incumplidas día a día, tal como queda al descubierto con casos como el de las defensoras Macarena Valdés y Nicolasa Quintremán.

Al respecto, la presente investigación propone que el incumplimiento de las obligaciones del Estado se da dentro de sus tres principales esferas: legislativa, judicial y administrativa.

En relación con la primera, es posible adjudicar responsabilidad en dos aristas. En primer lugar, existe una inactividad en torno a la creación de normativas que garanticen de manera efectiva la seguridad de las defensoras ambientales. En segundo lugar, es posible identificar una relación entre la aprobación irresponsable e inescrupulosa de tratados internacionales que tendrá como efecto la afectación al medio ambiente (como lo sería el actualmente en discusión TPP11) y la generación de escenarios de nuevos conflictos medioambientales.

En cuanto al Estado, como administrador y juez, la constante persecución y criminalización de las policías a las defensoras ambientales se yergue como una clara afectación a sus garantías fundamentales. Asimismo, es posible reconocer una marcada inactividad en la investigación y el esclarecimiento de los hechos constitutivos de delitos cuando estos tienen como víctimas a las defensoras ambientales. Un claro ejemplo de esta situación se da en el ya mencionado caso de la fallecida activista Macarena Valdés, respecto de quien las autoridades policiales se precipitaron a señalar el fallecimiento como un suicidio producido por la supuesta infidelidad de su pareja, procediendo a archivar el caso y desligándose de la investigación su papel de activista ambiental y las amenazas que ya había recibido. Ante la inactividad del Estado, los familiares y la comunidad de Macarena Valdés, solicitaron la realización de una segunda autopsia, la que se hizo de modo independiente. Esta segunda autopsia, realizada en enero de 2018, arrojo que no existían lesiones en Macarena que fuesen compatibles con la muerte por asfixia y que su cuerpo ya se encontraba sin vida cuando fue dispuesto para simular un suicidio.

En atención a la inactividad de los organismos llamados a cautelar la seguridad e integridad de las activistas ambientales, esta investigación incluyó la realización de una solicitud de información vía transparencia al Ministerio Público, pidiéndose información relativa a las instrucciones generales que fijen los criterios de actuación que deba adoptar el Ministerio Público frente a denuncias que se realicen por amenazas, hostigamientos, ataques violentos 
y agresiones sexuales que puedan sufrir mujeres activistas medioambientales en el contexto de su lucha por la protección del medio ambiente, solicitándose además cifras de los delitos que tienen como víctimas a las defensoras ambientales.

Como respuesta a dicha solicitud de información, el organismo señaló que no se han dictado instrucciones generales que fijen los criterios de actuación que Fiscalía debe adoptar frente a los delitos que sufren las activistas ambientales en el contexto de su lucha por la protección del medio ambiente, como tampoco cuentan con estadísticas referidas a los delitos sufridos por las defensoras.

\section{Acciones que pueden intentar las defensoras}

1. Denuncia (artículo 173 del Código Procesal Penal): No obstante poder realizarse ante la Fiscalía, Carabineros (policía) o Policía de Investigaciones, esta vía pierde efectividad cuando es la misma autoridad policial la que ejerce la violencia. Aunque no fuese así, dependiendo de la celeridad con que actúe cada unidad policial, la denuncia puede demorar semanas en ser entregada al Ministerio Público. Una vez derivada la denuncia al Ministerio Público, la investigación queda únicamente a cargo del fiscal, quien puede solicitar medidas cautelares para resguardar la seguridad de la víctima (artículo 6 CPP).

La denunciante no tiene una participación activa en el proceso y su intervención estará acotada al trato con el fiscal a cargo de su caso, lo que limita su posibilidad de acción e injerencia. Sumado a la sobrecarga de trabajo que tienen las y los fiscales, los prejuicios de clase, raza y género, que permean el ejercicio de la profesión, esta denuncia puede derivar en una postergación de la investigación, negligencia en la solicitud de medidas cautelares o el archivo de la causa-, dando por terminada la investigación sin juicio y sin conclusiones-, dejando a las víctimas en una situación de indefensión que puede durar meses, incluso años.

2. Querella (artículo 111 y sig. CPP): También interpuesta ante la jurisdicción penal; requiere el patrocinio de una abogada o abogado, lo que muchas veces actúa como barrera de acceso a la justicia debido a lo oneroso del servicio y a la ignorancia que tiene la población respecto de sus derechos; y también permite la solicitud de medidas cautelares a fin de resguardar la seguridad de la víctima. Si bien la querella implica un papel activo y directo de la víctima en el esclarecimiento de su caso, carece de las amplias facultades investigativas que sí tiene el Ministerio Público, dificultando la obtención de prueba que pueda alcanzar el alto estándar probatorio que rige la jurisdicción penal: más allá de toda duda razonable.

Si bien por esa vía pueden controlarse mejor los sesgos de Fiscalía, sigue existiendo el riesgo de que estos permeen la decisión del juez o de la jueza que conozca del caso, especialmente en territorios donde existe un álgido conflicto territorial o ambiental con predominancia de población indígena. Así, obtener una decisión favorable en esta instancia se torna del todo complejo.

3. Acciones constitucionales (artículos 20 y 21 de la Carta Fundamental): Ambas se presentan ante la corte de Apelaciones respectiva.

Acción de amparo (artículo $21 \mathrm{CPR}$ ): Puede interponerse por cualquier persona que sufra perturbación, privación 0 amenaza de sus derechos de libertad personal o seguridad individual, o que haya sido detenida, presa o arrestada con infracción a la constitución o a la ley.

Acción de Protección (artículo 20 CPR): Si buscare tutelarse el derecho a la vida, la integridad física o psíquica, inviolabilidad del hogar e incluso la igualdad ante la ley; la persona puede interponer una acción de protección, con el fin de que cese la vulneración a sus derechos fundamentales y se restablezca el imperio del derecho.

Ambas acciones tienen la ventaja de ser desformalizadas y de tramitación urgente. No obstante, la Corte de Apelaciones tiene severas limitaciones para hacer cesar la amenaza en caso de las defensoras ambientales, ya que no puede ordenar medidas cautelares gravosas, como la prisión preventiva, y carece de facultades investigativas. Típicamente, ordenará que se restablezca "el imperio del derecho" sin posibilidad de determinar las medidas específicas tendientes efectivamente a hacer cesar el acoso, con dificultad para identificar al sujeto obligado a cumplirlas, y sin posibilidad de dar seguimiento al cumplimiento de la sentencia. 


\section{Conclusiones}

La principal conclusión a la fue posible arribar, por medio de la presente investigación, es la palpable indefensión en que se encuentran actualmente las defensoras ambientales. La desigualdad de poderes que existe entre las activistas y las empresas a las que se enfrentan, el incumplimiento estatal de las obligaciones internacionales y constitucionales, el deficiente diseño en el sistema judicial y las acciones cautelares; , así como la inactividad de los organismos Ilamados a procurar la tutela de los derechos fundamentales de las defensoras, configuran un panorama en que las mujeres que se dedican al activismo ambiental están en claro riesgo y desprotección no contando con tutela judicial efectiva.

Como respuesta a esta constatación, se plantea la urgencia y necesidad de que Chile ratifique el Acuerdo de Escazú y adopte las medidas necesarias para la protección efectiva de defensoras y defensores medioambientales. En particular se recomienda la creación de una acción cautelar diseñada especialmente para proporcionar una vía judicial eficaz para la garantía de los derechos fundamentales de quienes se dedican al activismo ambiental.

Esta recomendación surge como consecuencia necesaria de la constatación de la insuficiencia que los mecanismos judiciales existentes implican para la situación de las activistas.

Finalmente, se requiere visibilizar la situación de las mujeres defensoras ambientales, formando y capacitando a los actores de los tres grandes poderes del Estado, en el entendido de que la gravedad de la situación denunciada requiere necesariamente de la unificación de los esfuerzos en pro de la consecución de la tutela judicial efectiva y la igualdad material.

\section{Referencias}

Acuña Ruz, F., Fredes García, D. y Pérez Valenzuela, D. (2010). Criminalización de la protesta \& judicialización de las demandas sociales. Derecho y Humanidades, 1(16), 363372. Recuperado de https://www.google.com/url?sa=t\& source=web\&rct=j\&url=https:// derechoyhumanidades . uchile.cl/index.php/RDH/article/download/16019/1653 5/\&ved=2ahUKEwjbyt-66oPmAhVKnJ4KHbH6BZoQFjAA egQIBhAB\&usg=AOvVaw3TKLT tywNCBkS-n4rDZMYX

Fernández Droguett, F. (2019). Extractivismo y patriarcado: La defensa de los territorios como defensa de la soberanía de los cuerpos. En S. Rojas Bravo (Coord.), Violencia estructural y feminismo: Apuntes para una discusión (pp. 29-37). Recuperado de http:// www.nomasviolenciacontramujeres.cl/wp-content/ uploads/2019/09/Violencia-Estructural-y-Feminismo.pdf

Follegati Montenegro, L. (2019). Violencia estructural y feminismo: Apuntes para una discusión. En S. Rojas Bravo (Coord.), Violencia estructural y feminismo: Apuntes para una discusión (pp. 17-27). Recuperado de http:// www.nomasviolenciacontramujeres.cl/wp-content/ uploads/2019/09/Violencia-Estructural-y-Feminismo.pdf

Fondo de Acción Urgente. (2015). Modalidades de criminalización y limitaciones a la efectiva participación de mujeres defensoras de derechos ambientales, los territorios y la naturaleza en las Américas. Recuperado de https://fondoaccionurgente.org.co/site/assets/files/1179/ espanol.pdf

Fondo de Acción Urgente. (2018). Impunidad de las violencias contra mujeres defensoras de los territorios, los bienes comunes y la naturaleza en América Latina. Recuperado de https://fondoaccionurgente.org.co/es/recursos/

Global Witness. (2017). ¿A qué precio? negocios irresponsables $y$ el asesinato de personas defensoras de la tierra $y$ del medio ambiente en 2017. Recuperado de https:// www.globalwitness.org/en/campaigns/environmentalactivists/a-qu\%C3\%A9-precio/

IniciativaMesoamericanadeMujeres Defensoras deDerechos Humanos. (2015). Agresiones contra defensoras de derechos humanos en Mesoamérica: Informe 20122014. Recuperado de https://im-defensoras.org/wpcontent/uploads/2016/04/283951300-Informe-20122014-de-Agresiones-contra-Defensoras-de-DDHH-enMesoamerica.pdf

Mies, M. y Shiva, V. (1998). La praxis del ecofeminismo: Biotecnología, consumo y reproducción. Barcelona, España: Icaria. 